\title{
Probing the Catalytic Efficiency of Supported Heteropoly Acids for Esterification: Effect of Weak Catalyst Support Interactions
}

\author{
Ali Alsalme ${ }^{D},{ }^{1}$ Aliyah A. Alsharif, ${ }^{1}$ Hamda Al-Enizi, ${ }^{1}$ Mujeeb Khan, ${ }^{1}$ Saad G. Alshammari, \\ Mshari A. Alotaibi, ${ }^{2}$ Rais Ahmad Khan $\left(\mathbb{1},{ }^{1}\right.$ and Mohammed Rafiq H. Siddiqui $\mathbb{C}^{1}$ \\ ${ }^{1}$ Department of Chemistry, College of Science, King Saud University, P.O. Box 2455, Riyadh 11451, Saudi Arabia \\ ${ }^{2}$ Department of Chemistry, College of Science and Humanities, Prince Sattam Bin Abdulaziz University, Alkharj, Saudi Arabia
}

Correspondence should be addressed to Ali Alsalme; aalsalme@ksu.edu.sa and Mohammed Rafiq H. Siddiqui; rafiqs@ksu.edu.sa

Received 16 May 2018; Revised 14 June 2018; Accepted 24 June 2018; Published 24 July 2018

Academic Editor: Antonio De Lucas-Consuegra

Copyright (c) 2018 Ali Alsalme et al. This is an open access article distributed under the Creative Commons Attribution License, which permits unrestricted use, distribution, and reproduction in any medium, provided the original work is properly cited.

\begin{abstract}
Supported heteropoly acids are an interesting class of solid acid catalysts which possess flexible structure and super acidic properties essentially required for the oil-based biodiesel production. In this study, a series of catalysts containing 25 wt.\% of heteropolytungstate (HPW) supported on various clays or $\mathrm{SiO}_{2}$ were prepared, and their catalytic efficiency was evaluated for esterification of acetic acid with heptanol. The as-prepared catalysts were characterized by various techniques including FT-IR spectroscopy, thermogravimetric analysis, X-ray diffraction, scanning electron microscopy, and BET. The catalytic efficiency of both bulk and supported HPW catalysts for the esterification activity strongly depends on the type of support and amount of catalyst; the bulk HPW catalyst and the catalyst supported by kaolinite with $25 \mathrm{wt}$.\% of HPW exhibited highest activity. In order to study the effect of temperature on conversion, all the catalysts were subjected to different reaction temperatures. It was revealed that esterification activity of both bulk and supported HPW catalysts strongly depends upon the temperature variations of the reaction. Besides, the effect of leaching of active sites on the catalysts performance for biodiesel production was also evaluated by inductively coupled plasma studies (ICP). The kaolinite-supported catalyst (25\% HPW/kaolinite) demonstrated higher amount of leaching which is also confirmed by the significant decrease in its catalytic activity when it is used for the second time. However, the higher activity demonstrated by HPW/kaolinite maybe because of some homogeneous reaction indicating a weak catalyst support interaction (WCSI) resulting in the leaching of the catalyst during the test. Furthermore, the effects of other reaction variables such as catalyst loading and reaction time on the conversion of acetic acid were also studied.
\end{abstract}

\section{Introduction}

Exhaustion of the world petroleum reserves and increasing demand for renewable energy sources have made biofuels an attractive alternative that can reduce the consumption of the traditional fossil fuels [1]. Besides, the emissions of greenhouse gasses from the burning of fossil fuels possess serious threat to both environment and human life [2]. Recently, biodiesel has generated immense interest as a suitable alternative to fossil fuels, which is nontoxic and biodegradable renewable fuel [3]. Biodiesel belongs to a class of fatty acid methyl ester, which is usually obtained from various natural resources including vegetable oils and animal fats [4]. These natural feedstocks are typically converted to biodiesel through a transesterification process in the presence of suitable catalysts [5]. Biodiesel does not contain any harmful substances and produces less dangerous emission to the environment and thus significantly contributes to minimize the emissions of toxic gases such as $\mathrm{SO}_{2}, \mathrm{SO}_{3}$, and $\mathrm{CO}$ [6]. Besides, biodiesel also contains higher lubricity, fewer emissions of carcinogenic particulate matter, and ease of storage, handling, and transport compared to conventional fossil fuel [7].

Biodiesel is commonly produced by transesterification of triglycerides of refined/edible types of oils using alcohol in presence of an acid or a basic catalyst [8]. Typically, the transesterification of vegetable oils and animal fats is carried 
out by using homogeneous basic catalysts, such as $\mathrm{KOH}$ and $\mathrm{NaOH}$, at mild temperatures [9]. Similarly, due to their Brønsted acidity, homogeneous acid catalysts such as $\mathrm{HCl}$ and $\mathrm{H}_{2} \mathrm{SO}_{4}$ are more appropriate for triglycerides from inedible oil, which promotes electrolytic activation of substrates [10]. Usually, homogeneous basic catalysts are more preferred over their acidic counterparts' due to their better activity, especially for triglycerides with low free fatty acid (FFA) contents [11]. However, homogeneous catalysts usually suffer from various problems including saponification, long transesterification reaction times, and corrosion. Apart from this, homogeneous catalysts are difficult to separate and recover after the reaction, which significantly increases the cost and seriously affects the economic viability of the process [12].

On the contrary, heterogeneous catalysts offer better alternative to their counterparts due to their ease of separation from the reaction medium [13, 14]. In addition, heterogeneous catalysts are less expensive, are easily available, possess longer durability, are easy to regenerate, and are more stable at high temperatures and pressure [15]. Therefore, advancement in the field of heterogeneous catalysis for the development of sustainable and efficient catalysts is highly desirable to minimize the cost of biodiesel production [16]. So far, several studies have been reported on biodiesel-related esterification reactions using various heterogeneous catalysts. For instance, Park et al. [17] examined the tungsten oxide zirconia, sulfated zirconia, and Amberlyst-15 catalysts for the conversion of used vegetable oils (VOs) to fatty acid methyl esters (FAMEs). Among them, tungsten oxide zirconia was a promising heterogeneous catalyst for the production of biodiesel fuels from used VOs because of high activity in the conversion over $93 \%$ and no leaching of $\mathrm{WO}_{3}$ in the esterification reaction. Still, the production of biodiesel is currently more expensive when compared to conventional diesel fuel because of its high raw material and production costs. To minimize the production cost of biodiesel, proper feedstock selection is highly required. Although the biodiesel feeds such as animal fats or used oils are cheaper, they contain high free fatty acid (FFA) when compared to without FFA VOs. However, the consumption of less expensive, high FFA acid feedstocks such as used oils in biodiesel production generally require large amount of catalysts and increased purification cost. Supported catalysts, such as dodecatungstophosphoric acid, dodecatungstosilicic acid, and dodecamolybdophosphoric acid, on acid-activated bentonite have been reported for esterification of acetic acid with primary, secondary, and tertiary butanol. [18].

To overcome the aforementioned problems, the FFAs are usually converted to alkyl esters in the presence of different types of acid catalysts including mineral acids, mesoporous materials, and supported catalysts, such as $\mathrm{H}_{2} \mathrm{SO}_{4}, \mathrm{HF}$, anionic resins, and heteropoly acids [19]. Among various acid catalysts, heteropoly acids (HPA) such as $\mathrm{H}_{3}\left[\mathrm{PW}_{12} \mathrm{O}_{40}\right]$, $\mathrm{H}_{4}\left[\mathrm{SiW}_{12} \mathrm{O}_{40}\right], \mathrm{H}_{3}\left[\mathrm{PMo}_{12} \mathrm{O}_{40}\right]$, and $\mathrm{H}_{4}\left[\mathrm{SiMo}_{12} \mathrm{O}_{40}\right]$ have attracted considerable attention. Due to their easy availability and cost-effectiveness, these catalysts offer more efficient and cleaner processes [20]. However, solid HPAs are usually suffering from deactivation during esterification reactions due to the formation of carbonaceous deposits (coke) on the catalyst surface. Notably, the conventional regeneration methods of burning coke at high temperatures at $500-550^{\circ} \mathrm{C}$ are not applicable to HPAs-based catalysts due to their inefficient thermal stability. In addition, the HPAs-based catalysts also possess low surface area $\left(1-10 \mathrm{~m}^{2} / \mathrm{g}\right)$ and solubility in various polar solvents [21]. Therefore, HPAs are generally dispersed on various supports to enhance their activity and make them more ecofriendly and less soluble solid acid catalysts with high thermal stability. So far, various types of supports including silica, active carbon, MCM-41, and clays with large surface area have been successfully applied for this purpose $[22,23]$. These supports not only enhance the active sites of the catalysts but also inhibit the formation of coke [5]. The acidity and catalytic activity of supported HPAs are strongly dependent on various parameters including the type of the support, amount of HPA loading, and conditions of pretreatment. Therefore, detail investigations of these parameters are highly desirable to enhance the catalytic activity of the HPAs-based solid acid catalysts.

In this study, heteropolytungstate (HPW) supported on various clays or $\mathrm{SiO}_{2}$ was prepared, and their catalytic efficiency was evaluated for esterification of acetic acid with heptanol (cf. Scheme 1). Detail investigations were carried out to determine various factors responsible for the catalytic efficiency of both bulk and supported HPW catalysts for the esterification reactions. The as-prepared HPAs-based supported catalysts were characterized using various microscopic and analytical techniques including X-ray powder diffraction (XRD), Fourier-transform infrared spectroscopy (FT-IR), thermogravimetric analysis, and scanning electron microscopy (TEM).

\section{Experimental}

2.1. Materials and Methods. Chemicals with high purity have been used without further purification. For catalyst preparation, ethanol (99.5\%), $\mathrm{H}_{3} \mathrm{PW}_{12} \mathrm{O}_{40}$ (HPW) (90\%), kaolinite $(\mathrm{K})$, bentonite $(\mathrm{B})$, montmorillonite $(\mathrm{M})$, and silica aerosol (S) $300\left(\mathrm{~S}_{\mathrm{BET}}, 300 \mathrm{~m}^{2} \mathrm{~g}^{-1}\right)$ and the reactants for the esterification reaction like acetic acid (99.3\%), heptanol (99\%), and dodecane (99.0\%) were purchased from Aldrich Chemicals. An Amberlyst-15 catalyst for comparison is obtained commercially.

2.2. Catalyst Preparation. All the supported HPW catalysts including HPW-S, HPW-K, HPW-B, and HPW-M are prepared via the wet impregnation method by using 25 wt. $\%$ of HPW. For this purpose, required amount of HPW is dissolved in ethanol by constant stirring, and subsequently, the respective amount of support (e.g., in case of HPW-S, silica was added) was slowly added to the HPW solution. The resultant solution was left for aging for $24 \mathrm{~h}$ to form slurry. The solvent was removed in a rotary evaporator. After this, no further pretreatments were applied to any of the materials, which were stored in air prior to analysis and reaction testing. 


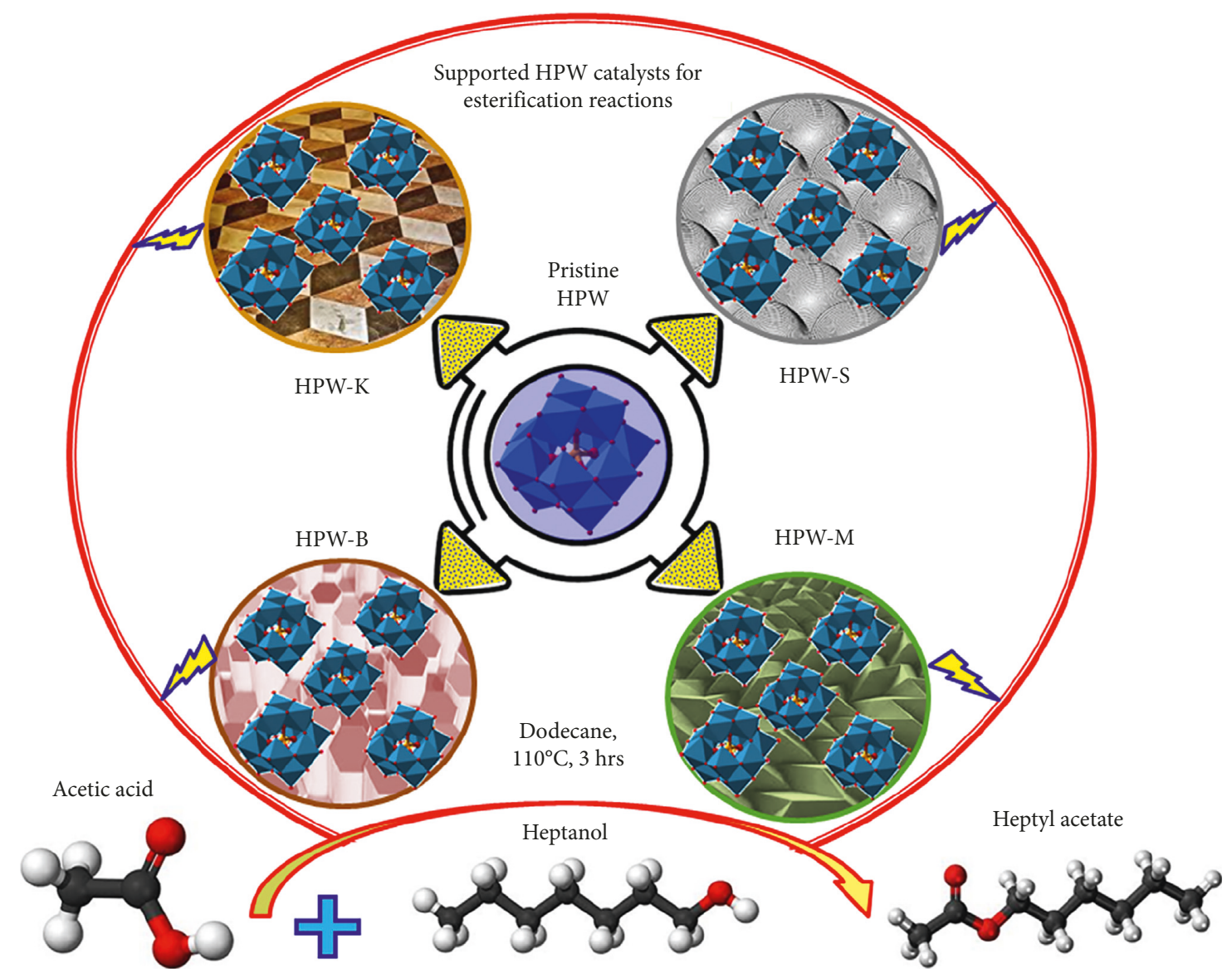

Scheme 1: Schematic representation of the preparation of clays or $\mathrm{SiO}_{2}$-supported heteropolytungstate (HPW) catalysts and their catalytic reaction for the esterification of acetic acid with heptanol.

2.3. Esterification of Acetic Acid. Liquid-phase esterification reactions were carried out in a $50 \mathrm{ml}$ glass reactor (roundbottom two-neck flask) equipped with a condenser and a magnetic stirrer at different temperatures (70, 90, and $110^{\circ} \mathrm{C}$ ) under atmospheric pressure. The total weight of reaction mixture (acetic acid + heptanol) was $10 \mathrm{~g}$. Dodecane $(2 \% \mathrm{w} / \mathrm{w})$ was added as a GC internal standard. Catalyst $(0.1 \mathrm{~g}$ and $0.02 \mathrm{~g})$ was added to reaction mixture. The reaction was carried out for $3 \mathrm{~h}$. To monitor the reaction, samples $(0.5 \mathrm{ml})$ of the reaction mixture were taken periodically, every twenty minutes. The sample for the analysis was separated from the catalyst by centrifugation. The samples were analyzed by gas chromatography.

2.4. Characterization. X-ray diffraction (XRD) patterns of the powdered samples were recorded on Ultima IV (Rigaku, Japan) X-ray powder diffractometer using $\mathrm{Cu} \mathrm{K} \alpha$ radiation $(\lambda=1.5418 \AA)$. The intensity data were collected over a $2 \theta$ range of $10-70^{\circ}$. The FT-IR spectra were recorded on a PerkinElmer FT-IR Spectrometer spectrum using the $\mathrm{KBr}$ disc method in the range of $400-4000 \mathrm{~cm}^{-1}$. Thermogravimetric analyses (TGA) were performed at temperatures between 100 and $600^{\circ} \mathrm{C}$ using Shimadzu TGA-50. Surface area measurements were performed by using Brunauer-Emmett-Teller (BET) method using a Micromeritics Surface Area and
Porosity (ASAP 2020 V3.01 E) instrument. Elements analyses were performed through inductively coupled plasma/mass spectrometer (ICP/MS) by PerkinElmer (NexION 300 D) instrument. The conversion of the catalytic products was analyzed using GC, 7890A, Agilent Technologies Inc., equipped with a flame ionization detector (FID) and a 19019S-001 HP-PONA column.

\section{Results and Discussion}

3.1. XRD Analysis. In order to study the effect of support on the catalytic activity of HPAs-based acid catalyst for the esterification reactions, various acid catalysts are prepared by using different supports. The catalysts such as $25 \%$ $\mathrm{HPW} / \mathrm{SiO}_{2}$ (HPW-S), 25\% HPW/kaolinite (HPW-K), 25\% HPW/bentonite (HPW-B), and 25\% HPW/montmorillonite (HPW-M) are synthesized by wet impregnation methods using 25 wt.\% heteropolytungstate (HPW) in each catalyst. All these catalysts are applied for the catalytic esterification of acetic acid with heptanol to produce heptyl acetate. Furthermore, the activities of these catalysts are also compared with catalytic activities of bulk HPW and Amberlyst@ 15 which were procured commercially. Initially, XRD spectra of all the supported catalysts are measured to confirm whether the HPW is present in the crystalline form or dispersed when supported. As shown in Figures 1(a) 


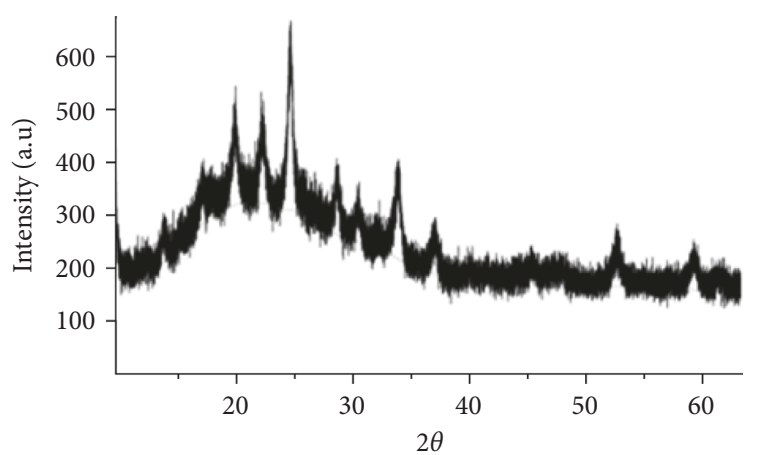

(a)

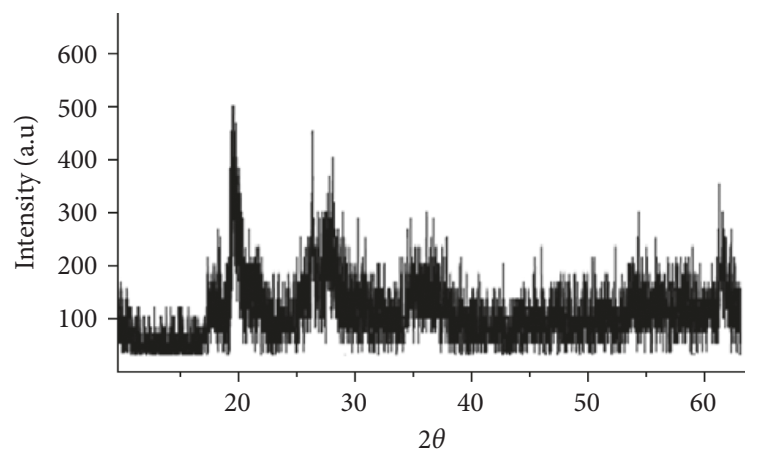

(c)

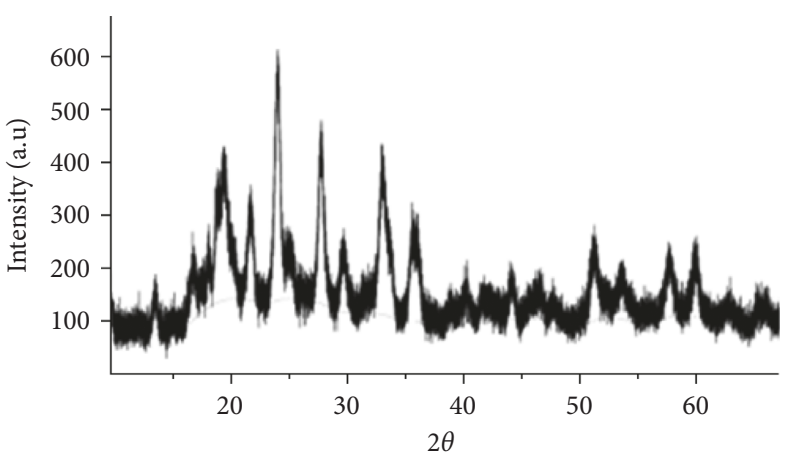

(b)

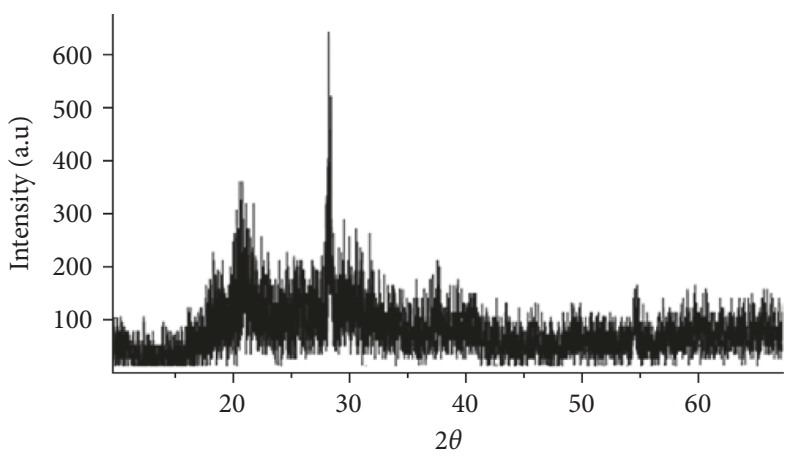

(d)

Figure 1: XRD diffractograms of (a) 25\% HPW/SiO 2 (HPW-S), (b) 25\% HPW/kaolinite (HPW-K), (c) 25\% HPW/bentonite (HPW-B), and (d) $25 \% \mathrm{HPW} /$ montmorillonite (HPW-M).

and 1(b), the XRD spectra of HPW-S and HPW-K showed clear diffraction peaks at $10.2^{\circ}, 20.6^{\circ}, 25.3^{\circ}, 29.4^{\circ}$, and $34.6^{\circ}$ which clearly corresponds to the typical Keggin structure of HPW, hence pointing towards the intact structure of HPW on the $\mathrm{SiO}_{2}$ support after impregnation [24]. These reflections in the corresponding XRD pattern also confirm the crystalline form of HPW in both HPW-S and HPW-K with a low intensity, indicating a possible spread of the catalyst on the support. Figures 1(c) and 1(d) exhibit the XRD spectra of HPW-B and HPW-M, respectively. The absence of reflections belonging to the HPW in the XRD spectrum of HPW-B potentially indicates the amorphous state of the HPW and points towards either the random distribution of HPW on the surface of bentonite or possible incorporation of HPW into the pores of the support [25]. However, the presence of a single intense peak at $2 \theta=27^{\circ}$ in the XRD spectrum of HPW-M indicates a good dispersion of HPW on the support which possibly led to a significant decrease in the intensity of the HPW reflections [26].

3.2. FT-IR Analysis. FT-IR is a promising technique to determine the structures of clay-supported HPW catalysts. Particularly, the absorption bands due to structural $\mathrm{OH}$ $\left(\sim 3700 \mathrm{~cm}^{-1}\right)$ and $\mathrm{Si}-\mathrm{O}\left(800\right.$ to $\left.1100 \mathrm{~cm}^{-1}\right)$ groups often play an important role for determining the structure. The FT-IR spectrum of the HPW-S is presented in Figure 2(a), which exhibited two bands around 983 and $895 \mathrm{~cm}^{-1}$, respectively, while the bands around 1105 and $811 \mathrm{~cm}^{-1}$ are attributed to the Keggin structure. Notably, the characteristic bands of HPW also appear in the same range from 800 to $1100 \mathrm{~cm}^{-1}$ which may overlap with the peaks of $\mathrm{SiO}_{2}$ [27]. For instance, three typical absorption peaks of HPW appear at $1072 \mathrm{~cm}^{-1}$ (P-O), $961 \mathrm{~cm}^{-1}(\mathrm{~W}=\mathrm{O})$, and $884 \mathrm{~cm}^{-1}$ (W-Oc-W) [28]. The presence of characteristic bands of both $\mathrm{SiO}_{2}$ and $\mathrm{HPW}$ with slight shifts, due to their interactions, clearly demonstrates that HPW in the sample still retains the Keggin structure. Similarly, the IR spectrum of HPW-K (cf. Figure 2(b)) showed bands at $810,985,1080$, and $1120 \mathrm{~cm}^{-1}$ pointing towards the presence of Keggin structure which remains intact after the impregnation process. Typically, the IR spectrum of kaolinite shows Si-O stretching and bending as well as $\mathrm{OH}$ bending absorptions in the $1300-400 \mathrm{~cm}^{-1}$ range. However, the $\mathrm{Si}-\mathrm{O}$ stretching vibrations of kaolinite give several well-resolved strong bands in the $1120-1000 \mathrm{~cm}^{-1}$ region. Therefore, the absorption around $1080 \mathrm{~cm}^{-1}$ in the HPW-K overlapped with the strong absorption of the kaolin peak around $1120 \mathrm{~cm}^{-1}$. These results are consistent with those reported in earlier study [29].

In the case of HPW-B, the primary structure of support was identified by five characteristic IR bands between 600 and $3000 \mathrm{~cm}^{-1}$, namely, the broad stretching band at 1052 to $1118 \mathrm{~cm}^{-1}$ was attributed to the $\mathrm{Si}-\mathrm{O}$ stretching vibration, and the shoulder at $926 \mathrm{~cm}^{-1}$ was indicative of $-\mathrm{OH}$ groups bonded to $\mathrm{Al}$ atoms. On the contrary, the bands at $524-820 \mathrm{~cm}^{-1}$ were assigned to $\mathrm{Si}-\mathrm{O}$ and $\mathrm{Si}-\mathrm{O}-\mathrm{Al}$ vibrations. As shown in Figure 2(c), the prominent peak at $820 \mathrm{~cm}^{-1}$ was attributed to interactions between HPW and the support 


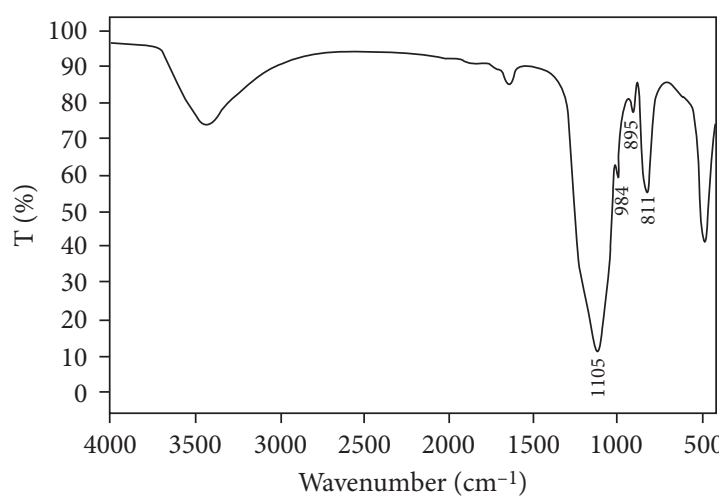

(a)

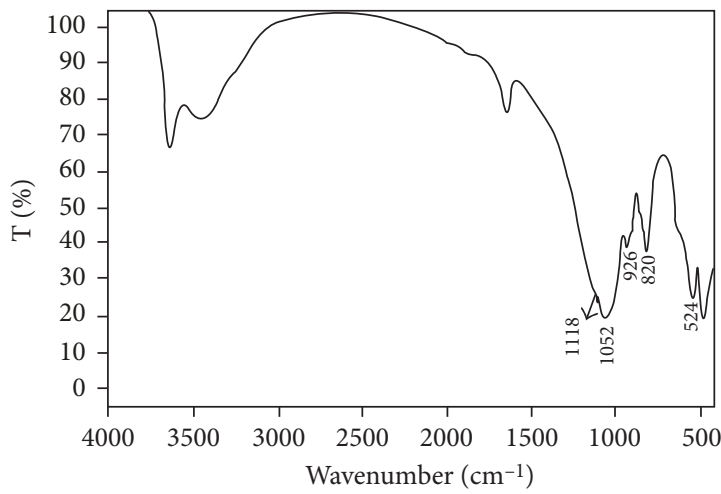

(c)

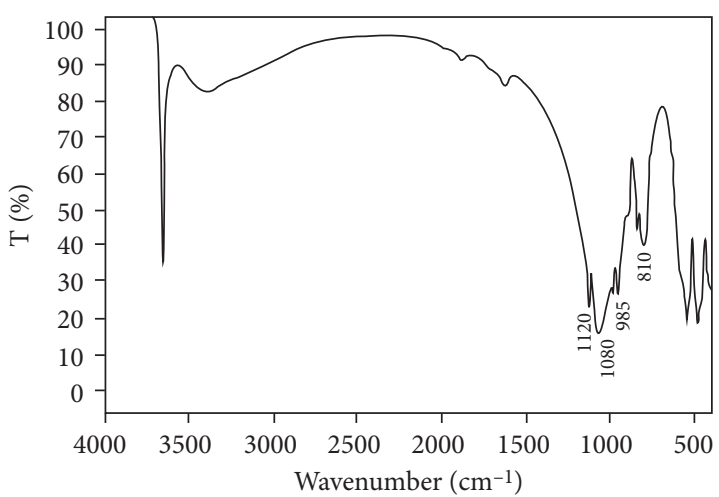

(b)

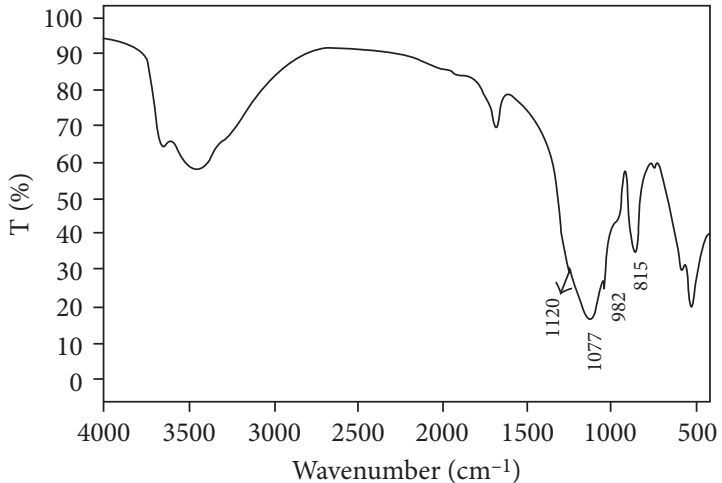

(d)

FiguRE 2: FT-IR spectra of (a) 25\% HPW/SiO 2 (HPW-S), (b) 25\% HPW/kaolinite (HPW-K), (c) 25\% HPW/bentonite (HPW-B), and (d) $25 \% \mathrm{HPW} /$ montmorillonite (HPW-M).

TABLE 1: The texture of various supported HPW catalysts obtained from nitrogen adsorption.

\begin{tabular}{lcccc}
\hline Catalyst & Calcination $\left({ }^{\circ} \mathrm{C}\right)$ & Surface area $\left(\mathrm{m}^{2} / \mathrm{g}\right)$ & Pore diameter $\left(\mathrm{A}^{\circ}\right)$ & Pore volume $\left(\mathrm{cm}^{3} / \mathrm{g}\right)$ \\
\hline HPW & 100 & 2 & 81 & 0.40 \\
HPW-S & 200 & 218 & 122 & 0.663 \\
HPW-K & 200 & 9 & 75 & 0.018 \\
HPW-B & 200 & 8 & 111 & 0.021 \\
HPW-M & 200 & 169 & 60 & 0.254 \\
\hline
\end{tabular}

[5]. Besides, the FT-IR spectra of the HPW-M sample in Figure 2(d) exhibited the band at $815 \mathrm{~cm}^{-1}$ which can be attributed to the formation of $\mathrm{Si}-\mathrm{O}-\mathrm{W}$ bonds, which may be due to the chemical interactions between the HPW and montmorillonite (MMT). Therefore, in the spectrum of the MMT sample, the band at $795 \mathrm{~cm}^{-1}$ was attributed to the symmetric stretching frequency of Si-O-Si [30].

3.3. BET Analysis. The surface areas of bulk HPW, HPW-S, HPW-K, HPW-B, and HPW-M were determined by the BET method from nitrogen adsorption-desorption isotherms which is summarized in Table 1 [31]. The texture (surface area, pore diameter, and pore volume) of bulk Keggin HPAs is well documented in the literature [32]. Table 1 shows that the catalyst HPW-S possesses relatively high surface area which is followed by HPW-M, whereas HPW-K and HPW-B showed almost similar and low surface area. In terms of pore diameter, HPW-S possessed larger pores size which is followed by HPW-B, whereas HPW-K and HPW-M have smaller pores.

The isotherms of silica-supported HPW (HPW-S) demonstrate a type IV pattern with a hysteresis loop (type H3) indicating the presence of nonuniform size and/or shape of mesopores $[33,34]$. The $\mathrm{N}_{2}$ adsorption-desorption isotherm of HPW-K showed type II isotherm which demonstrated that these materials possessed microporous structures. However, HPW-B and HPW-M demonstrate a type IV which points toward the presence of mesoporous materials with pores shapes of conical and cylindrical, respectively [35].

3.4. Catalytic Activity. Esterification of acetic acid with 1-heptanol was performed using a three-neck flask under atmospheric pressure at $90^{\circ} \mathrm{C}$. To prevent the evaporation of reactants, a cooling condenser was used. Initially, desired amount of acetic acid and catalyst were taken; the reaction 


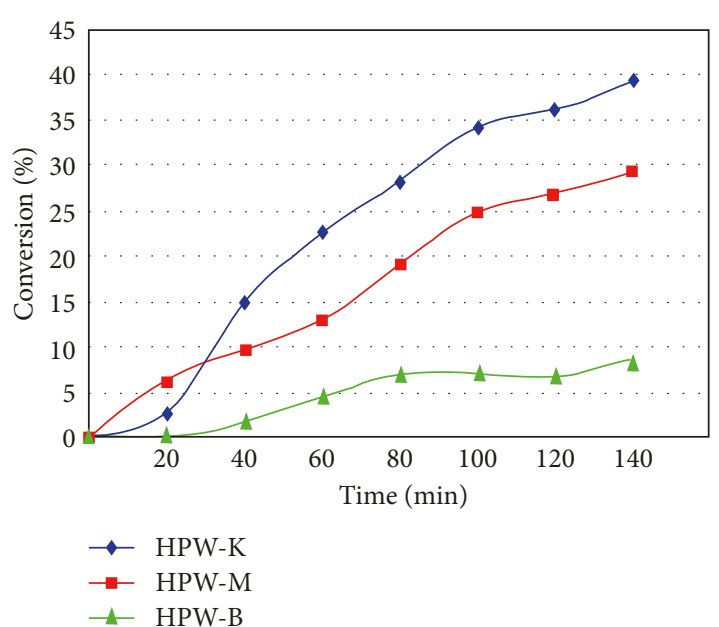

(a)

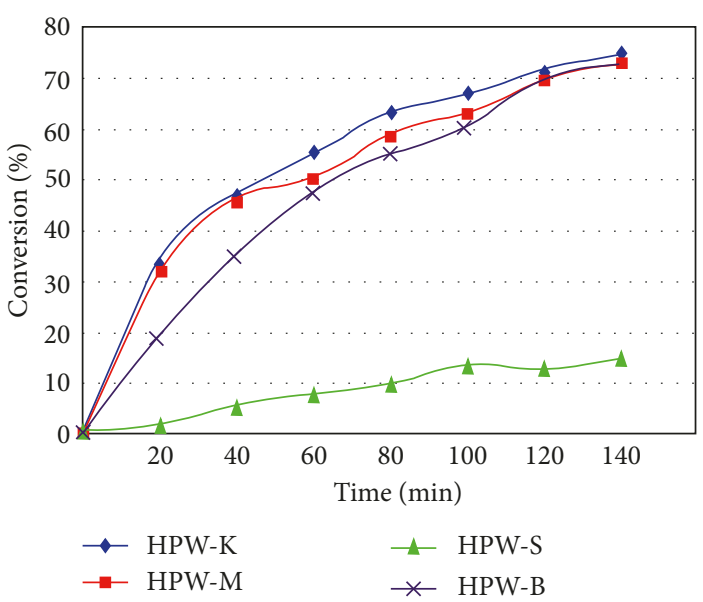

(b)

FIGURE 3: (a) Esterification of acetic acid with heptanol in the presence of HPW-K, HPW-M, and HPW-B using $0.02 \mathrm{~g}$ of catalysts. (b) Same esterification reactions carried out using $0.1 \mathrm{~g}$ of the catalyst. Notably, HPW-S showed extremely low catalytic activity when $0.02 \mathrm{~g}$ of the catalyst was used.

TABLE 2: Esterification of acetic acid with heptanol at $90^{\circ} \mathrm{C}$ using different amount of catalysts $(0.02$ and $0.1 \mathrm{~g})$.

\begin{tabular}{lcc}
\hline Catalyst & Catalyst weight $(\mathrm{g})$ & $\begin{array}{c}\text { Conversion }(\%) \\
140 \text { min }\end{array}$ \\
\hline $\mathrm{H}_{3} \mathrm{PW}_{12} \mathrm{O}_{40}$ (HPW) & 0.025 & 72 \\
$\mathrm{HPW}-\mathrm{K}$ & 0.1 & 100 \\
& 0.02 & 39 \\
$\mathrm{HPW}-\mathrm{B}$ & 0.1 & 75 \\
& 0.02 & 9 \\
HPW-M & 0.1 & 73 \\
& 0.02 & 30 \\
HPW-S & 0.1 & 73 \\
Amberlyst-15 & 0.02 & 7 \\
& 0.1 & 15 \\
\end{tabular}

mixture was heated, when the temperature reached $90^{\circ} \mathrm{C}$, and then required amount of 1-heptanol and dodecane were added, and the reaction was continued for three hours. To compare the catalytic activities of as-prepared catalysts, all reactions were performed under similar conditions by varying the catalysts. The esterification activity as a function of amount of the catalyst was studied, and the results are presented in Figure 3(a). It was revealed that the conversion increased by increasing the amount of catalyst (cf. Table 2). In case of bulk HPW, a conversion of $72.12 \%$ was obtained by using $0.025 \mathrm{~g}$ of catalyst in $140 \mathrm{~min}$, which is reached to $100 \%$ when the amount of the catalyst was increased to $0.1 \mathrm{~g}$. However, using same amount of Amberlyst@15 (0.1 g), a maximum conversion of $76.3 \%$ could be obtained under similar set of conditions. Notably, all the supported catalysts have demonstrated less conversion using higher amount of the catalyst $(0.1 \mathrm{~g})$ when compared to the bulk HPW.

However, among various supported catalysts, HPW-K has exhibited higher conversion of $75 \%$, which is followed by HPW-M, HPW-S, and HPW-B, respectively, as shown in Table 2. To study the effect of temperature on the esterification of acetic acid, several reactions are carried out at different temperatures such as 70,90 , and $110^{\circ} \mathrm{C}$ using the supported catalysts, and the results are presented in Figure 4. It is found that the conversion of acetic acid increased with increasing the temperature and amount of the catalyst, and higher conversion is obtained when HPW-K is used. All the results are summarized in Table 3.

Furthermore, an attempt was made to reuse the asprepared supported catalysts, including HPW-K, HPW-B, and HPW-M for the esterification of acetic acid. The regeneration of the catalysts after $3 \mathrm{~h}$ reaction time was conducted by simple filtration, washing with water for several times followed by calcination at $200^{\circ} \mathrm{C}$ in an oven, and they were used in the esterification reactions with a fresh reaction mixture. Notably, HPW-S was excluded for this study due to its low catalytic activity towards the acetic acid conversion even after using it in large amount at higher temperature. Indeed, this result is also corroborated from the literature [36]. It is reported that, although $\mathrm{SiO}_{2}$ exhibits large surface area (also observed in this study, $\mathrm{SiO}_{2}$ demonstrates a large surface area of $218 \mathrm{~m}^{2} / \mathrm{g}$ compared to other supported catalysts), it is a frequently used support for the $\mathrm{HPW}$ catalyst; however, $\mathrm{SiO}_{2}$-supported $\mathrm{HPW}$ often possess poor thermal stability, due to weak interaction between $\mathrm{HPW}$ and $\mathrm{SiO}_{2}$ [37]. Commonly, thermal decomposition of supported Keggin-type HPW catalysts may lead to a considerable loss of acidity, hence causing a decrease in the catalytic activity. Thus, the low catalytic activity of HPW-S towards the esterification of acetic acid could be explained from this behavior.

However, the other supported catalysts such as HPW-K, HPW-B, and HPW-M, which demonstrated a conversion of 100,35 , and $96 \%$ in the first run, have showed decreased catalytic activity of about 32,27 , and $42 \%$ in the second run, respectively, as shown in Figure 5. The decreased catalytic activities of the supported catalysts for the 2 nd run can be attributed to leaching of the catalysts [38]. 


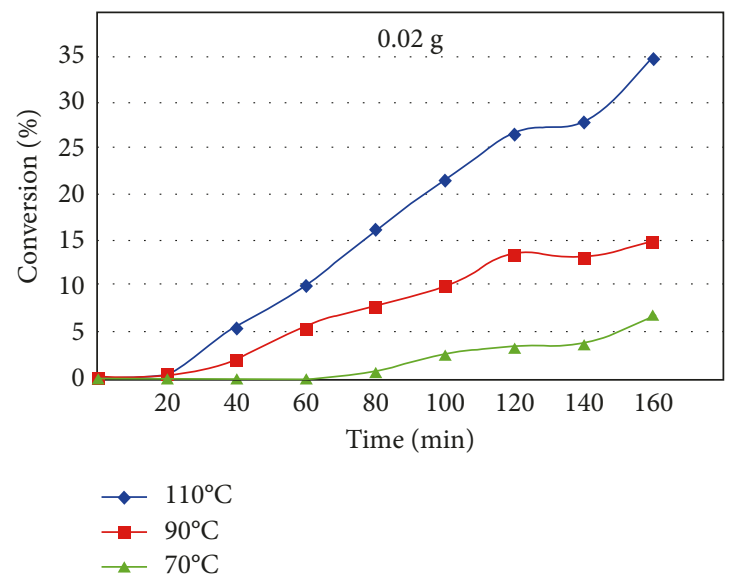

(a)

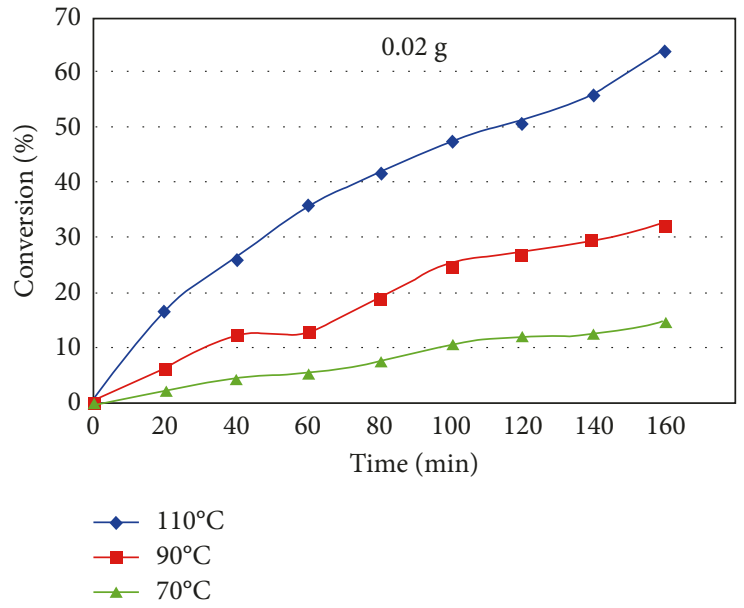

(c)

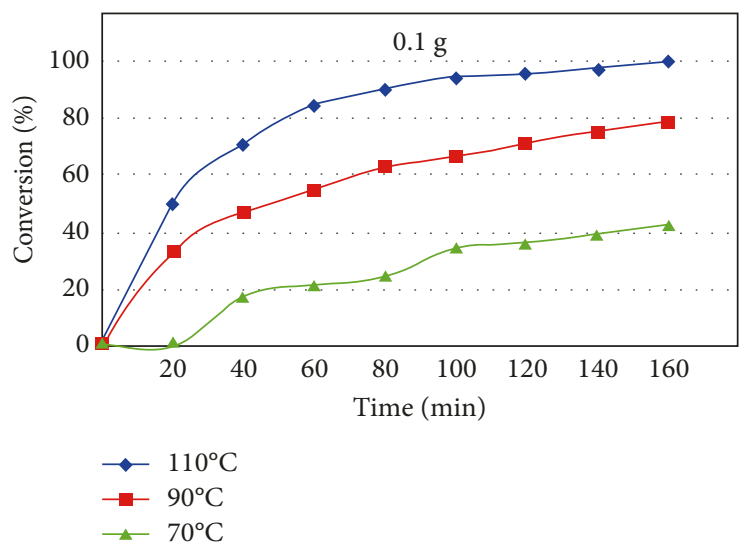

(e)

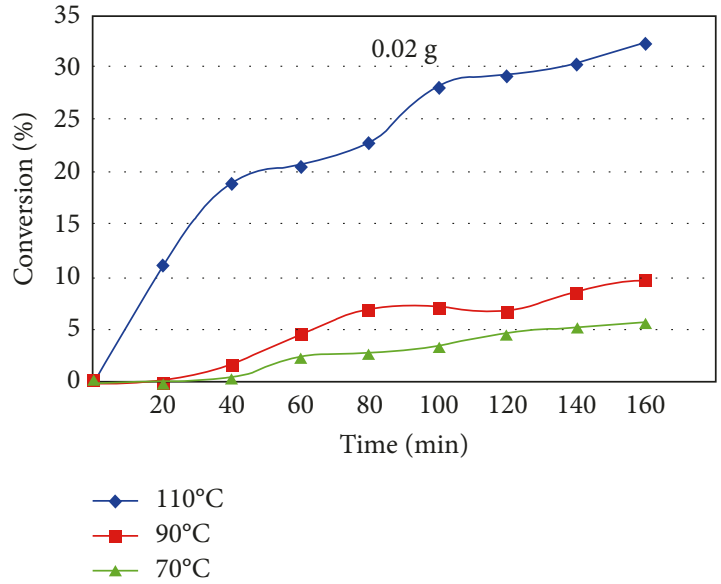

(b)

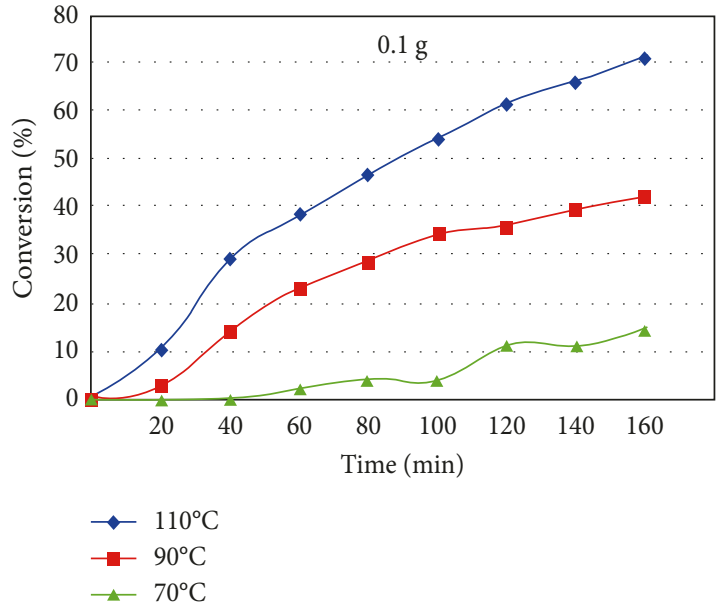

(d)

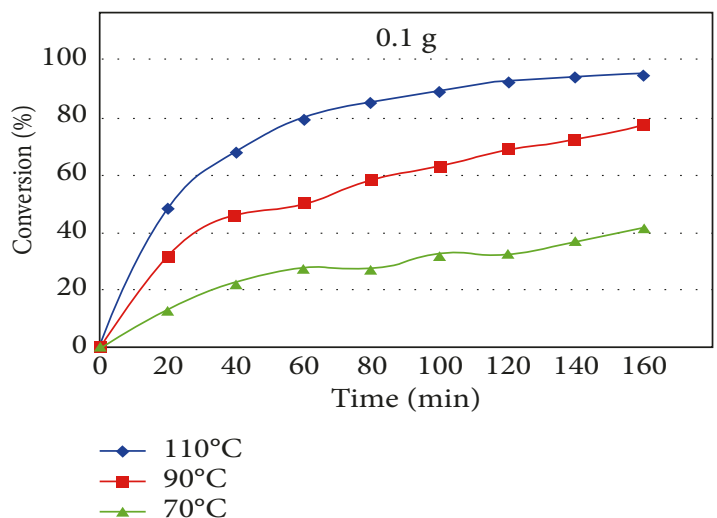

(f)

FIGURE 4: Effect of temperature on the catalytic activities of supported HPW catalysts for the esterification of acetic acid with heptanol. (a) HPW-K, 0.02 (g), (b) HPW-B, 0.02 (g), (c) HPW-M 0.02 (g), (d) HPW-K, 0.1 (g), (e) HPW-B, 0.1 (g), and (f) HPW-M, 0.1 (g).

Apart from this, the reuse of the solid catalysts is also governed by their extent of leaching in the reaction medium. With the aim of quantifying the amount of the catalyst which is being leached, solutions were analyzed by inductively coupled plasma (ICP), and the leaching percentages of the samples are summarized in Table 4. Indeed, the results obtained show the leaching of a fraction of all the supported catalysts. However, HPW-K exhibits higher amount of leaching when compared to HPW-B and HPW-M which also explains its decreased activity in the second run. It also 
TABLE 3: Effect of temperature on the catalytic activities of supported HPW catalysts for the esterification of acetic acid with heptanol.

\begin{tabular}{|c|c|c|c|c|c|}
\hline \multirow{2}{*}{ Catalyst } & \multirow{2}{*}{ Catalyst weight (g) } & \multirow{2}{*}{ Time (min) } & \multicolumn{3}{|c|}{ Conversion (\%) } \\
\hline & & & $70^{\circ} \mathrm{C}$ & $90^{\circ} \mathrm{C}$ & $110^{\circ} \mathrm{C}$ \\
\hline \multirow{2}{*}{ HPW-K } & 0.02 & 160 & 15 & 42 & 71 \\
\hline & 0.1 & 160 & 43 & 79 & 100 \\
\hline \multirow{2}{*}{ HPW-B } & 0.02 & 160 & 6 & 10 & 33 \\
\hline & 0.1 & 160 & 41 & 79 & 100 \\
\hline \multirow{2}{*}{ HPW-M } & 0.02 & 160 & 15 & 32 & 64 \\
\hline & 0.1 & 160 & 42 & 78 & 96 \\
\hline
\end{tabular}

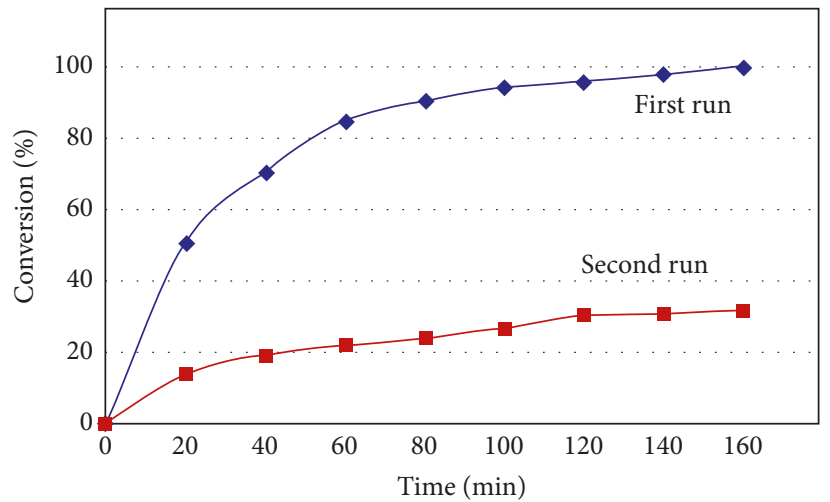

(a)

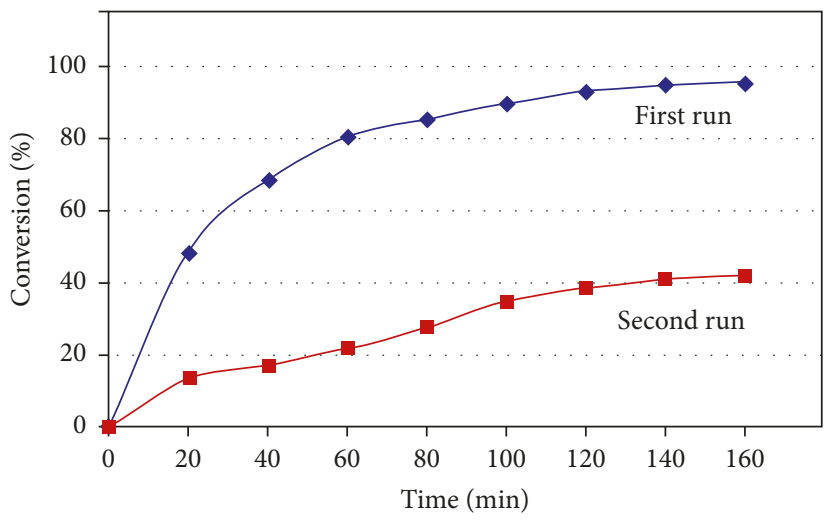

(c)

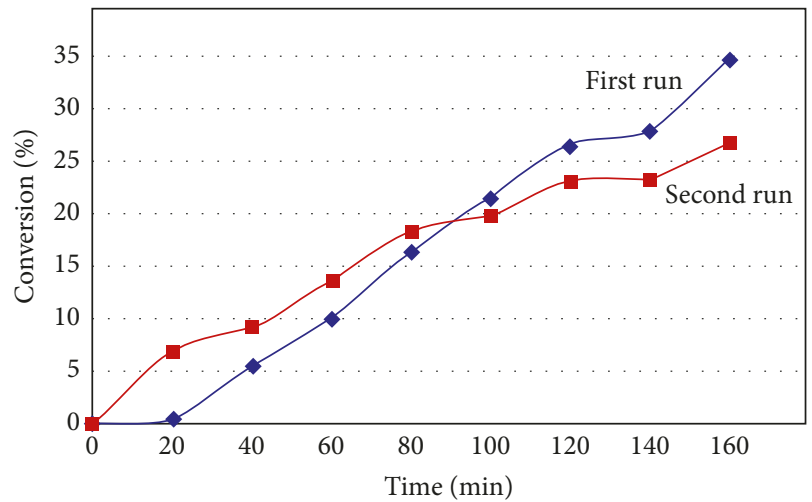

(b)

\begin{tabular}{lcccc}
\hline Catalyst & $\begin{array}{c}\text { Time } \\
(\mathrm{min})\end{array}$ & $\begin{array}{c}\text { Catalyst } \\
\text { weight } \\
(\mathrm{g})\end{array}$ & \multicolumn{2}{c}{ Conversion (\%) } \\
$110^{\circ} \mathrm{C}$ & 1st run & 2nd run \\
\hline HPW-K & 160 & 0.1 & 100 & 32 \\
HPW-B & 160 & 0.1 & 35 & 27 \\
HPW-M & 160 & 0.1 & 96 & 42 \\
\hline
\end{tabular}

(d)

FIGURE 5: Reuse of supported HPW catalysts for the esterification of acetic acid with heptanol in the presence of (a) HPW-K, (b) HPW-B, and (c) HPW-M, and (d) data shown in the form of table.

TABLE 4: Surface area and elemental analysis of tungsten $(W)$ in the catalyst for esterification of acetic acid with heptanol.

\begin{tabular}{lccc}
\hline Catalyst & $\begin{array}{c}\text { Surface area } \\
\left(\mathrm{m}^{2} / \mathrm{g}\right)\end{array}$ & $\begin{array}{c}W \% \text { before } \\
\text { reaction }\end{array}$ & $\begin{array}{c}W \% \text { after } \\
\text { reaction }\end{array}$ \\
\hline HPW-K & 9 & 2.4 & 0.5 \\
HPW-B & 8 & 0.8 & 0.6 \\
HPW-M & 169 & 1.6 & 0.7 \\
\hline
\end{tabular}

possesses a small surface area and low pore size. Furthermore, literature reports have revealed that the higher leaching of HPW-K can also be attributed to a complete breakdown of the crystalline structure of the leached kaolin compared to the parent kaolin, which leads to significant loss of the structure that facilitated the breakdown of kaolin's octahedral $\mathrm{AlO}_{6}$ structure [39]. Due to this, the crystalline nature of the HPW-K catalyst, which is demonstrated by its respective $\mathrm{XRD}$, deteriorates at the expense of increased amorphous phase. Indeed, HPW-K has showed best catalytic activity among all the catalysts in the first run (100\% conversion of acetic acid) due to its superior crystalline nature and better dispersion of HPW on the surface of kaolinite.

\section{Conclusion}

This work demonstrates that, among various supported Keggin-type heteropolytungstate (HPW) catalysts, the HPW supported on kaolinite ( $\mathrm{HPW}-\mathrm{K})$ is much more active and stable than those on silica, bentonite, montmorillonite, and bulk HPW for the esterification of acetic acid. The high 
catalytic activity of HPW-K is attributed to the effective Brønsted acid sites of the catalysts and preservation of the HPW Keggin structure in highly dispersed states in HPW-K. From the catalytic data obtained, it can be concluded that the catalytic activity does not solely depend on the surface area of the support as HPW-K shows high catalytic activity, although its surface area is comparable to HPW-B. The higher activity demonstrated by HPW-K maybe because of the weak catalyst support interaction resulting in the leaching of the catalyst during the test, resulting in some homogeneous reaction. This is further supported by substantial lowering of the catalytic activity in the second run for HPW-K and HPW-M. However, for HPW-B which does not show a very high catalytic activity in the first run, the lowering of the activity in second run is less pronounced. This reflects in the elemental analysis carried out for the catalysts before and after the reaction, which shows lesser catalyst loss for HPW-B compared with HPW-K and HPWM. Furthermore, it was revealed that esterification activity of both bulk and supported HPW catalysts strongly depend upon the temperature variations of the reaction. This type of comparative study of various supports and its findings could be important for the model reactions for the production of biodiesel, in view of searching for more effective supports with improved thermal stability to survive repeated regenerations.

\section{Data Availability}

The characterization and catalytic data used to support the findings of this study are included within the article.

\section{Conflicts of Interest}

The authors declare that there are no conflicts of interest regarding the publication of this article.

\section{Acknowledgments}

The authors extend their appreciation to the Deanship of Scientific Research at King Saud University for funding this work through the Research Group no. RG-1438-006. This project was supported by the Deanship of Scientific Research at Sattam Bin Abdulaziz University under the Research Project 2013/01/136.

\section{References}

[1] J. M. Bergthorson and J. T. Murray, "A review of the combustion and emissions properties of advanced transportation biofuels and their impact on existing and future engines," Renewable Sustainable Energy Reviews, vol. 42, pp. 1393-1417, 2015.

[2] M. Mofijur, H. H. Masjuki, M. A. Kalam et al., "Effect of biodiesel from various feedstocks on combustion characteristics, engine durability and materials compatibility: a review," Renewable Sustainable Energy Reviews, vol. 28, pp. 441-455, 2013.

[3] L. F. Chuah, J. J. Klemeš, S. Yusup, A. Bokhari, and M. M. Akbar, "A review of cleaner intensification technologies in biodiesel production," Journal of Cleaner Production, vol. 146, pp. 181-193, 2016.

[4] B. Norjannah, H. C. Ong, H. H. Masjuki, J. C. Juan, and W. T. Chong, "Enzymatic transesterification for biodiesel production: a comprehensive review," RSC Advances, vol. 6, no. 65, pp. 60034-60055, 2016.

[5] M. R. Avhad and J. M. Marchetti, "Innovation in solid heterogeneous catalysis for the generation of economically viable and ecofriendly biodiesel: a review," Catalysis Reviews, vol. 58, no. 2, pp. 157-2018, 2016.

[6] Z. Sajid, F. Khan, and Y. Zhang, "Process simulation and life cycle analysis of biodiesel production," Renewable Energy, vol. 85, pp. 945-952, 2016.

[7] A. K. Agarwal, T. Gupta, P. C. Shukla, and A. Dhar, "Particulate emissions from biodiesel fuelled CI engines," Energy Conversion and Management, vol. 94, pp. 311-330, 2015.

[8] P. A. Alaba, M. S. Yahaya, and W. M. A. W. Daud, "Efficient biodiesel production via solid superacid catalysis: a critical review on recent breakthrough," RSC Advances, vol. 6, no. 82, pp. 78351-78368, 2016.

[9] D. Lima, A. Lúcia, C. M. Ronconi, and C. J. A. Mota, "Heterogeneous basic catalysts for biodiesel production," Catalysis Science and Technology, vol. 6, no. 9, pp. 2877-2891, 2016.

[10] M. Kour and P. Satya, "Sulfonated carbon/nano-metal oxide composites: a novel and recyclable solid acid catalyst for organic synthesis in benign reaction media," New Journal of Chemistry, vol. 39, no. 8, pp. 6338-6350, 2015.

[11] H. A. Farag, A. El-Maghraby, and N. A. Taha, "Transesterification of esterified mixed oil for biodiesel production," International Journal of Chemical and Biological Sciences, vol. 2, pp. 105-114, 2012.

[12] P. Carlo, B. Emanuele, D. M. Guido, L. Antonio, M. Giuseppe, and M. Giuseppe, "Recoverable and reusable aluminium solvated species used as a homogeneous catalyst for biodiesel production from brown grease," Applied Catalysis A: General, vol. 501, pp. 48-55, 2015.

[13] F. Liu, L. Wang, Q. Sun, L. Zhu, X. Meng, and F.-S. Xiao, "Transesterification catalyzed by ionic liquids on superhydrophobic mesoporous polymers: heterogeneous catalysts that are faster than homogeneous catalysts," Journal of the American Chemical Society, vol. 134, no. 41, pp. 16948-16950, 2012.

[14] M. Farooq, A. Ramli, and A. Naeem, "Effect of different metal oxides on the catalytic activity of $\gamma-\mathrm{Al}_{2} \mathrm{O}_{3}-\mathrm{MgO}$ supported bifunctional heterogeneous catalyst in biodiesel production from WCO," RSC Advances, vol. 6, no. 2, pp. 872-881, 2016.

[15] M. E. Borges and L. Díaz, "Recent developments on heterogeneous catalysts for biodiesel production by oil esterification and transesterification reactions: a review," Renewable Sustainable Energy Reviews, vol. 16, no. 5, pp. 2839-2849, 2012.

[16] M. Atadashi, A. Aroua, A. Aziz, and N. Sulaiman, "The effects of catalysts in biodiesel production: a review," Journal of Industrial and Engineering Chemistry, vol. 19, no. 1, pp. 14-26, 2013.

[17] Y. M. Park, D. W. Lee, D. K. Kim, J. Lee, and K. Y. Lee, “The heterogeneous catalyst system for the continuous conversion of free fatty acids in used vegetable oils for the production of biodiesel," Catalysis Today, vol. 131, no. 1-4, pp. 238-243, 2008.

[18] S. K. Bhorodwaj and D. K. Dutta, "Activated clay supported heteropoly acid catalysts for esterification of acetic acid with butanol," Applied Clay Science, vol. 53, no. 2, pp. 347-352, 2011. 
[19] F. G. Cirujano, A. Corma, and F. L. I. Xamena, "Zirconiumcontaining metal organic frameworks as solid acid catalysts for the esterification of free fatty acids: Synthesis of biodiesel and other compounds of interest," Catalysis Today, vol. 257, pp. 213-220, 2015.

[20] A. E. Kerenkan, B. François, and D. Trong-On, "Chemically catalyzed oxidative cleavage of unsaturated fatty acids and their derivatives into valuable products for industrial applications: a review and perspective," Catalysis Science and Technology, vol. 6, no. 4, pp. 971-987, 2016.

[21] Y. Huang and F. Yao, "Hydrolysis of cellulose to glucose by solid acid catalysts," Green Chemistry, vol. 15, no. 5, pp. 1095-1111, 2013.

[22] J. Alcaniz-Monge, G. Trautwein, and J. P. Marco-Lozar, "Biodiesel production by acid catalysis with heteropolyacids supported on activated carbon fibers," Applied Catalysis A: General, vol. 468, pp. 432-441, 2013.

[23] F. Su and Y. Guo, "Advancements in solid acid catalysts for biodiesel production," Green Chemistry, vol. 16, no. 6, pp. 2934-2957, 2014.

[24] S.-H. Chai, H.-P. Wang, Y. Liang, and B.-Q. Xu, "Sustainable production of acrolein: gas-phase dehydration of glycerol over 12-tungstophosphoric acid supported on $\mathrm{ZrO}_{2}$ and $\mathrm{SiO}_{2}$," Green Chemistry, vol. 10, no. 10, pp. 1087-1093, 2008.

[25] L. Rožić, B. Grbić, N. Radić et al., "Mesoporous 12-tungstophosphoric acid/activated bentonite catalysts for oxidation of 2-propanol," Applied Clay Science, vol. 53, no. 2, pp. 151156, 2011.

[26] V. V. Bokade and G. D. Yadav, "Synthesis of bio-diesel and bio-lubricant by transesterification of vegetable oil with lower and higher alcohols over heteropolyacids supported by clay (K-10)," Process Safety and Environmental Protection, vol. 85, no. 5, pp. 372-377, 2007.

[27] W. Kuang, A. Rives, M. Fournier, and R. Hubaut, "Structure and reactivity of silica-supported 12-tungstophosphoric acid," Applied Catalysis A: General, vol. 250, no. 2, pp. 221-229, 2003.

[28] O. da Silva Lacerda, R. M. Cavalcanti, T. M. de Matos, R. S. Angélica, G. N. da Rocha Filho, and I. D. C. L. Barros, "Esterification of oleic acid using 12-tungstophosphoric supported in flint kaolin of the Amazonia," Fuel, vol. 108, pp. 604-611, 2013.

[29] J. Madejová, "FTIR techniques in clay mineral studies," Vibrational Spectroscopy, vol. 31, no. 1, pp. 1-10, 2003.

[30] L. Hu, S. Ji, Z. Jiang, H. Song, P. Wu, and Q. Liu, "Direct synthesis and structural characteristics of ordered SBA-15 mesoporous silica containing tungsten oxides and tungsten carbides," Journal of Physical Chemistry C, vol. 111, no. 42, pp. 15173-15184, 2007.

[31] M. A. Parent and J. B. Moffat, "Cation/proton interactions and acid strengths in salts of 12-tungstophosphoric acid prepared from 1A, 1B and 3B monovalent cations," Catalysis Letters, vol. 48, no. 3-4, pp. 135-143, 1997.

[32] T. Okuhara, N. Mizuno, and M. Misono, "Catalysis by heteropoly compounds-recent developments," Applied Catalysis A: General, vol. 222, no. 1-2, pp. 63-77, 2001.

[33] C. Shi, M. Xin, R. Wang et al., "Synthesis and characterization of a new mesoporous $\mathrm{HPW} / \mathrm{SiO}_{2}$ composite material," Chemical Journal of Chinese Universities, vol. 26, pp. 1198-1201, 2005.

[34] M. Kruk, M. Jaroniec, C. H. Ko, and R. Ryoo, "Characterization of the porous structure of SBA-15," Chemistry of Materials, vol. 12, no. 7, pp. 1961-1968, 2000.

[35] F. Rojas, I. Kornhauser, C. Felipe et al., "Capillary condensation in heterogeneous mesoporous networks consisting of variable connectivity and pore-size correlation," Physical Chemistry Chemical Physics, vol. 4, no. 11, pp. 2346-2355, 2002.

[36] I. V. Kozhevnikov, "Catalysis by heteropoly acids and multicomponent polyoxometalates in liquid-phase reactions," Chemical Reviews, vol. 98, no. 1, pp. 171-198, 1998.

[37] B. Olthof, A. Khodakov, A. T. Bell, and E. Iglesia, "Effects of support composition and pretreatment conditions on the structure of vanadia dispersed on $\mathrm{SiO}_{2}, \mathrm{Al}_{2} \mathrm{O}_{3}, \mathrm{TiO}_{2}, \mathrm{ZrO}_{2}$, and $\mathrm{HfO}_{2}$," Journal of Physical Chemistry B, vol. 104, no. 7, pp. 1516-1528, 2000.

[38] Y. C. Sharma, B. Singh, and J. Korstad, "Advancements in solid acid catalysts for ecofriendly and economically viable synthesis of biodiesel," Biofuels, Bioproducts and Biorefining, vol. 5, no. 1, pp. 69-92, 2011.

[39] L. A. S. do Nascimento, L. M. Tito, R. S. Angélica, C. E. Da Costa, J. R. Zamian, and G. N. da Rocha Filho, "Esterification of oleic acid over solid acid catalysts prepared from Amazon flint kaolin," Applied Catalysis B: Environmental, vol. 101, no. 3-4, pp. 495-503, 2011. 

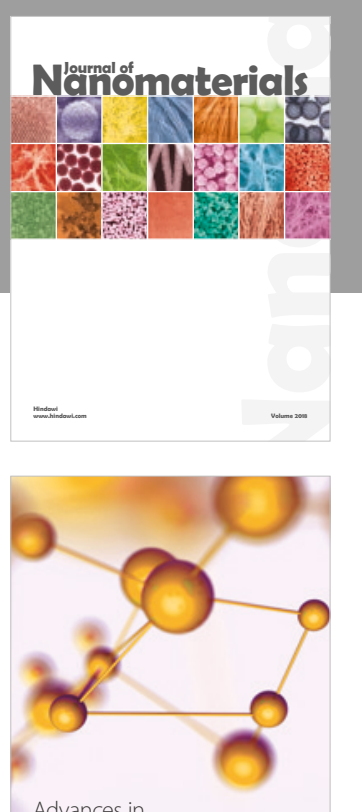

Physical Chemistry
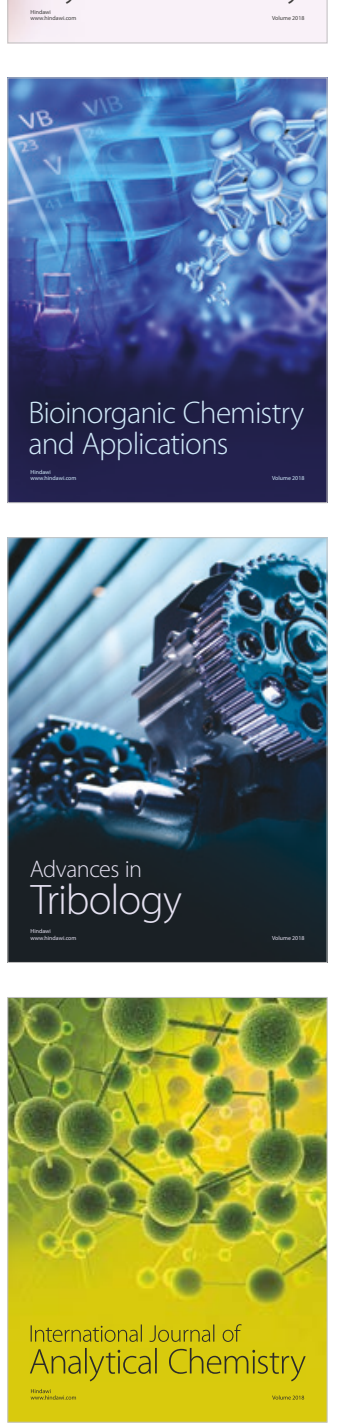

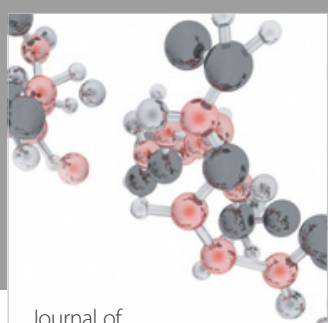

Analytical Methods

in Chemistry

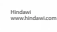

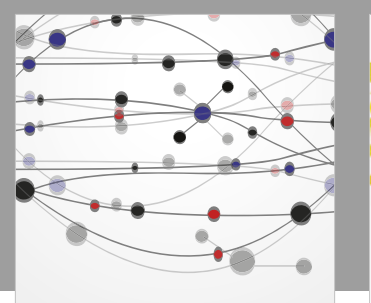

The Scientific World Journal

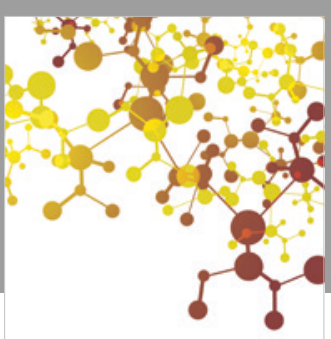

Journal of

Applied Chemistry
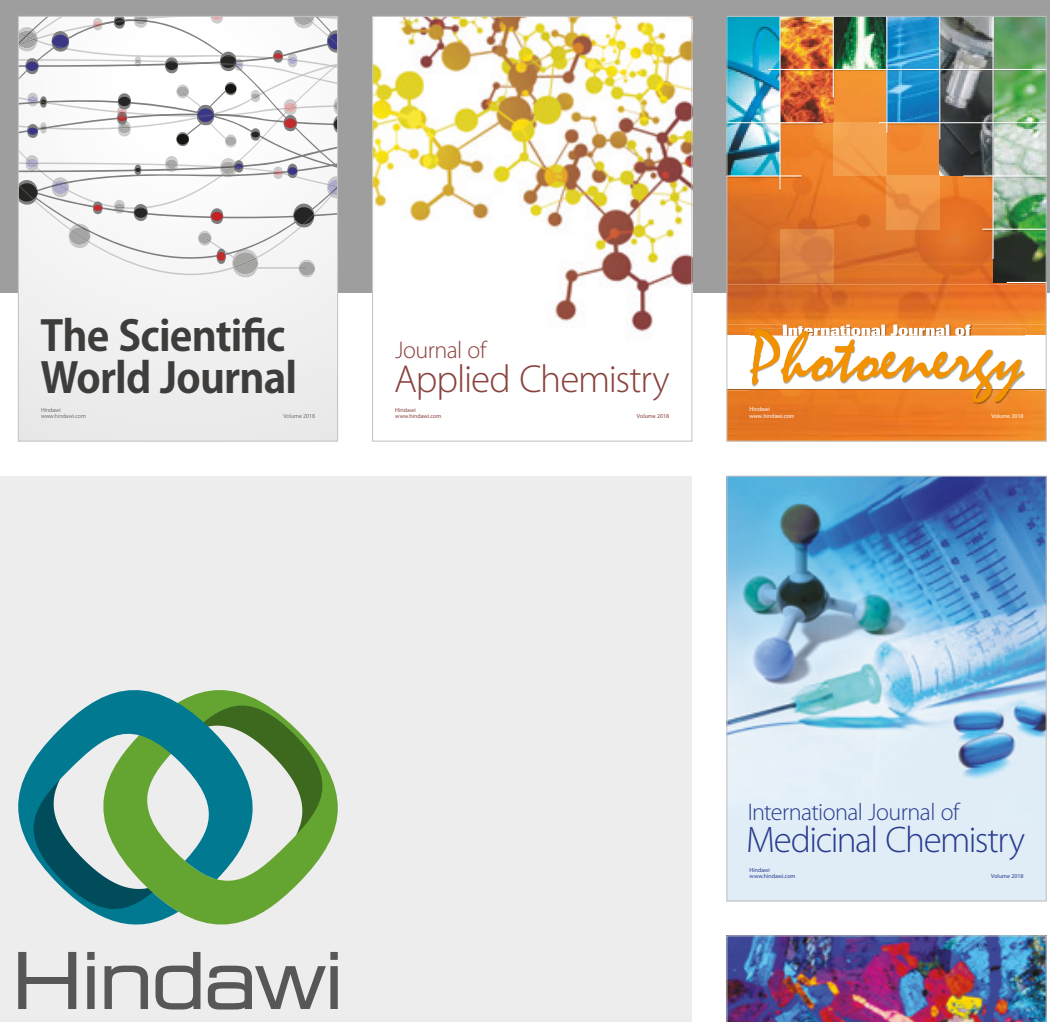

Submit your manuscripts at

www.hindawi.com
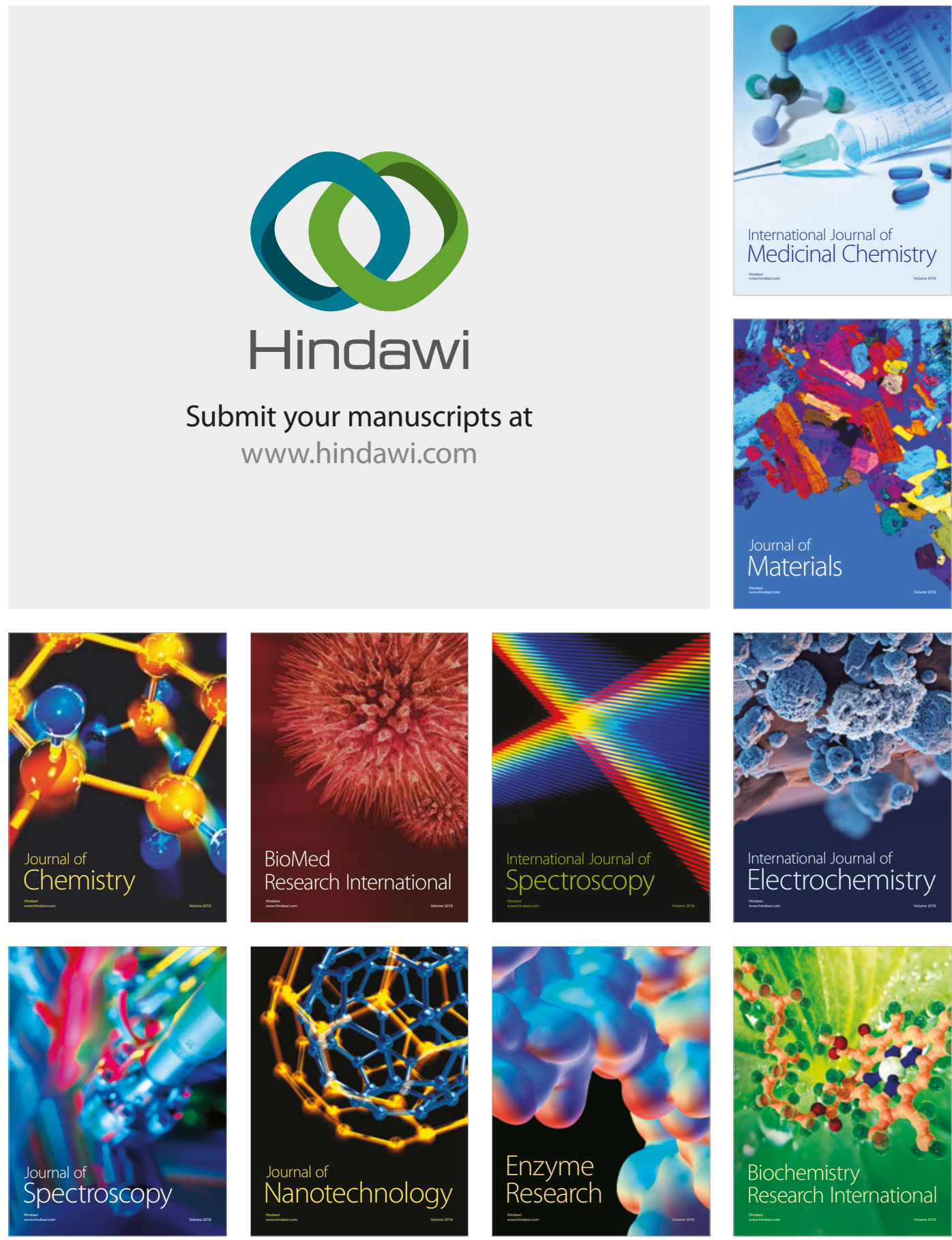
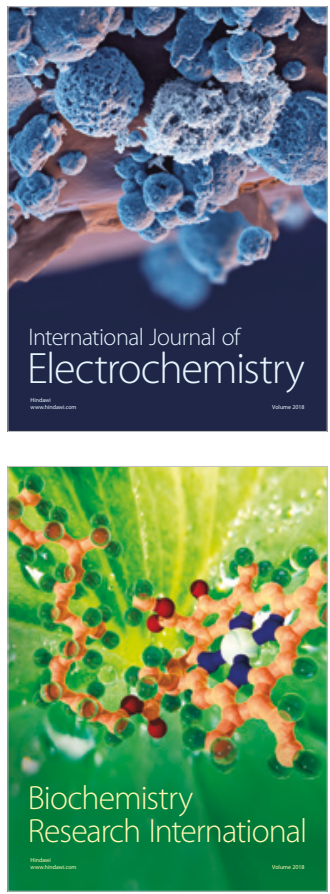